Semina $\square \quad \mathrm{Nr} 14$

Scientiarum 2015

s. $49-59$

DOI: http://dx.doi.org/10.15633/ss.1078

Piotr Urbańczyk

\title{
Koncepcja automatyzacji \\ Leonarda Torresa y Quevedo \\ jako przyczynek do rozwoju computer science
}

Esej o automatyce ${ }^{1}$ został opublikowany w styczniu 1914 roku nakładem Hiszpańskiej Królewskiej Akademii Nauk. Jego autorem jest inżynier i wynalazca - Leonardo Torres y Quevedo ${ }^{2}$ (18521936). Jak przekonuje Brian Randell, należał on do niewielkiego grona osób, które na początku XX wieku w pełni uznawało znaczenie idei Charlesa Babbage'a zawartych w planach maszyny analitycznej ${ }^{3}$. Celem niniejszej pracy jest wskazanie, że rozwiązania

1 W niniejszej pracy posługuję się angielskim tłumaczeniem dzieła, znajdującym się w The Origins of Digital Computers: Selected Papers, ed. B. Randell, Berlin-Heidelberg-New York 1982.

2 Zgodnie z hiszpańską tradycją swoje podwójne nazwisko odziedziczył on po matce (Valentina Quevedo de la Maza) i ojcu (Luis Torres Vildbsolo y Urquijo). Urodził się 28 grudnia 1852 roku w Santa Cruz de Igufia, małej wsi położonej w północnej części Hiszpanii. Swoją podstawową edukację otrzymał w Bilbao (Hiszpania) i Paryżu oraz Madrycie, gdzie ukończył politechnikę. Skonstruował wiele niesamowitych wynalazków, wśród nich kolejkę liniową nad wodospadem Niagara, sterowiec wykorzystywany przez Francję podczas I wojny światowej, pierwsze na świecie urządzenie sterowane drogą radiową i w końcu pierwszy na świecie automat do rozgrywania końcówek szachowych. Nie ulega wątpliwości, że praca nad tymi maszynami doprowadziła go do idei zawartych w Eseju... Pozwalam sobie jednak pominąć tę kwestię. Na temat wymienionych powyżej wynalazków istnieje dość bogata literatura, w większości w języku hiszpańskim.

3 B. Randell, From Analytical Engine to Electronic Digital Computer: The Contributions of Ludgate, Torres, and Bush, „Annals of the History of Computing” 4 (1982), s. 327. 
zawarte $\mathrm{w}$ owym krótkim eseju stanowią istotne ogniwo między koncepcjami Babbage'a a XX-wieczną computer science.

\section{Definicja i klasyfikacja automatyki}

Na uwagę zasługują już wstępne zagadnienia Eseju o automatyce, w których Torres y Quevedo definiuje przedmiot swoich rozważań. Zaczyna od pojęcia automatu. Po pierwsze jest to maszyna, która imituje wygląd i ruchy człowieka lub zwierzęcia, posiada własne źródło napędu i wykonuje zawsze te same działania bez żadnych manipulacji z zewnatrz. Automaty tego rodzaju były znane co najmniej od czasów Oświecenia. Na podobnej zasadzie działały np. automaty Vaucansona ${ }^{4}$. Drugim typem automatów są maszyny imitujące nie tyle proste gesty, co akty myślowe (dokładniej: przemyślane działanie) człowieka.

Automaty drugiego typu podlegają kolejnemu podziałowi, którego podstawą jest sposób regulacji działania maszyny. W pierwszym przypadku maszyna może być kontrolowana przez określone warunki w sposób ciąły, w drugim warunki regulujace działanie maszyny pojawiaja się nagle. Przykładem automatu pierwszego typu jest torpeda żyroskopowa. By działała prawidłowo, należy ustanowić stałą mechaniczną relację między jej ruchomymi częściami. Problem ustanowienia tej relacji jest jednym z wielu, jakie rozważa się na gruncie kinematyki stosowanej w kontekście konstrukcji maszyn. Automatyzacja maszyn drugiego typu nie polega na ustanowieniu stałej mechanicznej relacji - ich celem jest szybka zmiana działania w reakcji na odpowiednie okoliczności. Mówiąc bardziej współczesnym językiem, maszyny tego rodzaju muszą potrafić operować na zmiennych dyskretnych, w przeciwieństwie do maszyn analogowych, które pracują na zmiennych ciagłych ${ }^{5}$. Jak

4 Zob. H. Vigneron, Les Automates, „La Nature” 2141 (1914), s. 56.

5 Zob. F. G. González de Posada, F. A. G. González Redondo, Leonardo Torres Quevedo (1852-1936). 2a Parte: Automática, máquinas analiticas, „La Gaceta de la RSME” vol. 8.1 (2005), s. 275. 
zauważa Torres, praca automatów drugiego typu (czyli regulowanych w sposób dyskretny) nie jest przedmiotem rozważań kinematyki, a badanie takich maszyn nigdy wcześniej nie zostało podjęte w sposób systematyczny. Zdaniem hiszpańskiego inżyniera jest to zadanie automatyki, którą należy wyodrębnić jako część inżynierii maszynowej ${ }^{6}$.

\section{Robotyka i sztuczna inteligencja}

Pierwszym zadaniem automatyki byłoby zbadanie środków konstrukcyjnych potrzebnych do osiagnięcia pożądanych wzorców zachowania. Według Torresa y Quevedo automaty powinny:

1. posiadać „,narządy zmysłów”, tj. termometry, kompasy magnetyczne, dynamometry, manometry i tak dalej. Mówiąc inaczej, powinny być wyposażone w sensory reagujące na warunki, które maja wpływ na zachowanie maszyny;

2. posiadać układy wykonawcze, czyli ,kończyny, tj. urządzenia lub mechanizmy zdolne do wykonania operacji, do których sa przeznaczone ${ }^{7 "}$;

3. powinny także być wyposażone w źródło zasilania o dowolnej postaci;

4. w końcu, automaty muszą być zdolne do odpowiedniego rozeznania, tj. powinny w każdym momencie być w stanie uwzględnić informacje, które otrzymuja, a nawet te, które otrzymały wcześniej. „Konieczne jest, by automaty imitowały istoty żywe w regulowaniu swoich działań według tego, co dostają na wejściu, i dostosowały swoje zachowanie do zmieniajacych się warunków".

Torres y Quevedo zdawał sobie sprawę, że budowa mechanizmów, które pełniłyby rolę sensorów automatu, może nieść za sobą pewne praktyczne trudności. Podkreślał jednak, że w teorii podob-

6 Zob. L. Torres y Quevedo, Essays on Automatics. Its Definition - Theoretical Extent of Its Applications, [w:] The Origins of Digital Computers, dz. cyt., s. 89-90.

7 L. Torres y Quevedo, Essays on Automatics..., dz. cyt., s. 90.

8 L. Torres y Quevedo, Essays on Automatics..., dz. cyt., s. 90. 
ne trudności nie występuja. Uwaga ta połączona jest z pewnego rodzaju optymizmem:

Każdy dzień przynosi nowe instrumenty wynalezione w celu pomiaru i zapisu różnego rodzaju danych pochodzacych ze zjawisk świata fizycznego. To, co nie może zostać zmierzone dzisiaj, będzie zmierzone jutro lub bardzo niedługo i - wierzę, że wyrażam tutaj ogólnie akceptowaną opinię - nie ma powodów, by uważać inaczej ${ }^{9}$.

Podobna uwaga i ten sam optymizm dotyczą konstrukcji mechanizmów mających spełniać funkcję efektorów (układów wykonawczych): ,nikt nie może zaprzeczyć możliwości wynalezienia maszyny wykonującej określoną [dowolna - P. U.] operację"10.

Podsumowując, automat to maszyna, która w większym lub mniejszym stopniu działa zależnie od okoliczności, zgodnie z dowolnymi regułami, które można na nią nałożyć podczas konstrukcji. Jak przekonuje Torres, budowa takiej maszyny jest możliwa przynajmniej z czysto teoretycznego punktu widzenia. Wydaje się, że nie ma przeszkód, by powyższe rozważania traktować jako podwaliny dzisiejszej robotyki, a nawet - abstrahując od fizycznych implementacji takich maszyn - sztucznej inteligencji ${ }^{11}$.

\section{Technika elektromechaniczna}

Zdaniem Torresa konstrukcji automatu można dokonać na wiele różnych sposobów. On sam w eseju z 1914 roku zaproponował metodę elektromechaniczna, która - jego zdaniem - jest metodą najbardziej ogólną. Należy zauważyć, że Torres y Quevedo był

9 L. Torres y Quevedo, Essays on Automatics..., dz. cyt., s. 90.

10 L. Torres y Quevedo, Essays on Automatics..., dz. cyt., s. 90.

11 Definicja automatu Torresa jest tożsama z podstawową definicją tzw. inteligentnego agenta. Por. S. Russell, P. Norvig, Artificial Intelligence: A Modern Approach, Prentice Hall 2009, rozdział 2. Podział automatów Torresa y Quevedo jest także częściowo zbieżny z zawartym w tym podręczniku podziałem systemów inteligentnych. Por. L. Torres y Quevedo, Essays on Automatics..., dz. cyt., rozdział 1. 
przede wszystkim inżynierem. Można więc przypuszczać, że na takie podejście do problemu konstrukcji automatów naprowadziły go rozwiązania, które stosował przy tworzeniu swoich maszyn. Z pewnościa jest pionierem stosowania tej metody na gruncie automatów i, jak zauważa Randell, wydaje się, że główną motywacją pracy Torresa jest pełne wykorzystanie nowych możliwości, które oferowała technika elektromechaniczna oraz zmierzenie się z przyjętymi poglądami na temat ograniczeń maszyn ${ }^{12}$.

Technika zaproponowana w Eseju o automatyce jest bardzo prosta. Zmiana warunków regulujących pracę automatu jest przekładana na ruch. W ten sposób przesunięty zostaje przełącznik wyposażony w szczotkę poruszającą się nad linią styków. Jeśli mamy $n$ przełączników, a symbolem $P_{\mathrm{k}}$ oznaczymy zbiór styków skojarzonych z przełącznikiem $k$, liczba pozycji, w których może znaleźć się system, będzie równa mocy produktu iloczynu kartezjańskiego o postaci $P_{1} \times P_{2} \times \ldots P_{n}$. Z każdą taka pozycją związany jest przekaźnik, czyli elektromagnes, którego wzbudzenie powoduje przesunięcie zbliżonej do niego ruchomej metalowej części, która zamyka kolejny obwód i inicjuje określoną operację. Można dowolnie zwiększać liczbę przełączników i skojarzonych z nimi styków, a więc i liczbę przypadków, od których zależeć będzie zachowanie automatu. Mówiąc inaczej, można je dowolnie komplikować - przynajmniej do momentu, w którym nie wychodzimy poza obszar teoretycznych rozważań.

\section{Kartezjusz vs. chatbot}

Ponieważ dowolnie duża liczba przełączników i styków daje w konsekwencji dowolnie skomplikowane zachowania automatu, czasem może się wydawać, że maszyna myśli lub przeprowadza rozumowanie samodzielnie. Zdaniem Torresa jest to podstawowy błąd, który popełniają ludzie rozważający to zagadnienie.

12 B. Randell, From Analytical Engine to Electronic Digital Computer, dz. cyt., s. 333. 
W tym miejscu Eseju o automatyce przywołany został Kartezjusz. W świetle jego dualistycznej filozofii ciało jest wyrafinowana maszyną stworzona przez Boga - o wiele bardziej skomplikowaną od jakiejkolwiek maszyny, którą może skonstruować człowiek. Kartezjusz argumentował, że gdybyśmy mieli przed sobą maszynę imitujacca wygląd i zachowanie małpy lub jakiekolwiek zwierzęcia pozbawionego władz rozumowych, nie moglibyśmy w żaden sposób ustalić, czy nie posiada ona tej samej natury, co te zwierzęta. Kartezjusz odmawiał jednak możliwości skonstruowania maszyny imitujaccej te spośród zachowań człowieka, które sa kontrolowane przez rozum - jest metafizycznie niemożliwe, by automat używał słów w celu sensownej odpowiedzi na to, co zostało mu powiedziane ${ }^{13}$.

Torres rozważył teoretyczną możliwość zbudowania maszyny, która posiadałaby ogromną liczbę przełączników poruszających się po stykach odpowiadających wszystkim znakom alfabetu (literom, liczbom, znakom interpunkcyjnym i tym podobnym). Z każdym wyrażeniem korespondowałaby pewna pozycja systemu, a więc i elektromagnes. Niech elektromagnes uruchamia fonograf, na którym nagrana została odpowiedź na pytanie, które wywołało wzbudzenie elektromagnesu. Otrzymamy wtedy maszynę zdolną do dyskusji de omni re scibili, a więc odpowiednik dzisiejszych chatbotów.

Torres zdaje sobie sprawę, że wykonanie takiej maszyny może być bardzo trudne, nie trudniejsze jednak od budowy maszyny, która przekonywająco imitowałaby istotę żywą.

Uwaga ta musi być dobrze zrozumiana. Torres mimo swojego entuzjastycznego podejścia nie utrzymuje, że możliwe jest skonstruowanie maszyn myślących czy też - posługując się późniejszą terminologia - sztucznej inteligencji (w tak zwanej „silnej wersji”). Próbuje jedynie argumentować za tym, że podział przedstawiony przez Kartezjusza nie jest ważny. Francuski myśliciel nie zwrócił uwagi na to, że w celu podania sensownej odpowiedzi automat nie

13 Por. R. Descartes, Rozprawa o metodzie, tłum. W. Wojciechowska, Kraków 1950, s. 44-46. 
musi sam przeprowadzać rozumowania. Rozumowanie przeprowadza za niego konstruktor.

Jego dystans do kwestii myślenia maszyn został dobrze podsumowany w „Scientific American”, który relacjonując paryską wystawę maszyn Torresa y Quevedo, informuje o możliwościach maszyny do gry w szachy: „Oczywiście, nie twierdzi się, że potrafi ona myśleć lub dokonywać rzeczy, w których myślenie jest konieczne, aczkolwiek jej konstruktor uważa, że granice, wśród których myślenie jest koniecznie potrzebne, powinny zostać lepiej zdefiniowane"14.

\section{Maszyna analityczna}

Mimo optymistycznego podejścia do inżynieryjnych możliwości budowy maszyn Torres zdaje sobie sprawę również z praktycznych trudności związanych z konstrukcją tych mechanizmów, które w automatach miałyby pełnić funkcję sensorów i efektorów. Zauważa jednak, że niedogodności te znikaja, jeśli rozważamy konstrukcję maszyn liczących - do sprawnego działania nie potrzebuja one takich urządzeń. Analiza tego rodzaju maszyn ma tę dodatkową zaletę, że wypracowane w niej rozwiązania moga zostać łatwo uogólnione na wszystkie automaty.

Oczywiście rozważania Torresa dotyczą maszyny analitycznej ${ }^{15}$. By właściwie dokonywać obliczeń, powinna być ona zdolna do przeprowadzenia następujących elementarnych operacji:

1. zapis i przechowywanie określonej wartości;

2. wykonywanie czterech podstawowych działań arytmetycznych (dodawanie odejmowanie, mnożenie i dzielenie);

3. porównywanie dwóch wielkości;

4. wydruk danych.

14 Torres and His Remarkable Automatic Devices, „Scientific American Supplement”, nr 2079 (1915), s. 297.

15 To jest takiej, która może obliczyć dowolną funkcję dla danych na wejściu wartości zmiennych. Torres twierdzi, że taką maszynę lepiej byłoby nazwać ,,arytmetyczną. Pozostaje jednak przy nomenklaturze Babbage'a. 
Torres nie poprzestawał jednak na prostym wyliczeniu. Wskazał konkretne metody uzyskania powyższych funkcjonalności przy wykorzystaniu stosowanej przez niego techniki elektromechanicznej.

Wreszcie hiszpański wynalazca podał konkretny przykład konstrukcji maszyny arytmetycznej. Oblicza ona formułę $a x(y-z)^{2}$, drukuje wynik i informuje o zakończeniu swoich operacji. Rezultat ten może zostać osiagnięty poprzez zastosowanie odpowiedniego układu śrub, sprężyn, ciężarków, przełączników, obwodów i przekaźników. Programowanie takiego automatu polega na użyciu wymienialnych bębnów, na których za pomoca odpowiednio ułożonych styków można uruchamiać i wyłączać jego poszczególne elementarne operacje. Esej o automatyce zawiera nie tylko dokładny opis takiej maszyny, lecz także jej ogólne schematy.

\section{Znaczenie algorytmów}

Pozwolę sobie pominąć detale związane z technologią wykonania przedstawionej przez Torresa maszyny. Niech wystarczy uwaga, że jego rozwiązanie jest niesłychanie ciekawe i choć dziś wydaje się dosyć archaiczne, zastosowanie go w obszarze maszyn liczacych okazało się rewolucyjne. Przejdę natomiast do komentarza, który w Eseju o automatyce znajduje się bezpośrednio po szczegółowym opisie maszyny obliczającej wspomnianą formułę.

Torres y Quevedo zwraca uwagę, że automaty zachowają się dokładnie jak istoty inteligentne, które postępują według pewnych reguł - ale zachowują się w ten sposób jedynie wtedy, gdy konieczne jest wybranie drogi działania dla każdego konkretnego przypad$\mathrm{ku}^{16}$. ,Inteligentne” zachowanie maszyny nie polega na tym, że potrafi ona przeprowadzać obliczenia arytmetyczne, lecz na tym, że potrafi je wykonywać ściśle według pewnych ustalonych procedur.

Na przykład praca opisywanej przez Torresa maszyny zależeć będzie od wyniku porównania wartości zmiennych y i z. Gdy sa

16 Zob. L. Torres y Quevedo, Essays on Automatics..., dz. cyt., s. 100. 
one równe, maszyna drukuje wynik 0 i czeka na zakończenie cyklu; gdy nie sa równe, maszyna podnosi do kwadratu wynik odejmowania mniejszej wielkości od większej i przeprowadza dwa kolejne mnożenia.

Jak zauważa autor Eseju, powyższy przykład jest bardzo prosty, lecz użyta metoda ma dosyć ogólny charakter. Jego uwaga ma ogromne znaczenie, ponieważ to od tej kwestii zależeć będzie zakres automatyki. Torres przewidział, że potencjał maszyn analitycznych czy też - bardziej ogólnie - automatów nie tkwi w technikach wykorzystywanych przy ich konstrukcji czy nawet w ich mocy obliczeniowej, ale w możliwościach (i ograniczeniach) implementacji algorytmów.

\section{Metoda zmiennopozycyjna}

Kolejna uwaga, jaka Torres czyni na temat przedstawionej przez niego maszyny, dotyczy tego, że jej praktyczna realizacja może okazać się niemożliwa - jednak nie ze względu na proponowane środki konstrukcyjne. Jeśli maszyna ma obliczać jedynie liczby o ograniczonej wielkości, powiedzmy do 100, może zostać skonstruowana w sposób, który został podany w Eseju o automatyce. Trudności moga pojawić się w wyniku operowania dużymi liczbami, które są tak samo kłopotliwe w obliczeniach mechanicznych, jak tradycyjnych obliczeniach dokonywanych przez ludzi.

Torres podaje rozwiązanie tego problemu. Jak pisze w Eseju..., polega ono na wykorzystaniu zasad notacji dziesiętnej ${ }^{17}$.

Czasem, by uniknać pisania wielu zer, wielkości mogą być zapisane jako $n \times 10^{m}$. Możemy znacząco uprościć tę notację poprzez arbitralne ustanowienie trzech prostych reguł:

- $n$ będzie zawsze zawierało tę samą liczbę cyfr (na przykład sześć).

- Pierwsza cyfra $n$ będzie liczbą dziesiątek, druga setek, itd.

- Każdą wielkość będzie się zapisywać w postaci: $n ; m$.

17 L. Torres y Quevedo, Essays on Automatics..., dz. cyt., s. 102. 
A zatem, zamiast 2435.27 i 0:00000341862 będzie się pisać odpowiednio i $243527 ; 4$ i $341862 ;-5$.

W ten sposób udaje się zredukować liczbę elementarnych operacji, które automat musi wykonać podczas obliczeń. To proste rozwiąanie praktycznego problemu było milowym krokiem. Metoda zmiennopozycyjna bardzo ułatwiała pracę nie tylko maszynie Torresa, ale i komputerom, które powstawały w XX wieku. Esej o automatyce zawierał pierwszą propozycję tej idei ${ }^{18}$, która niezależnie rozwijana była później przez Konrada Zusego.

\section{Zakończenie}

Ostanie strony Eseju o automatyce zawierają uwagi o wyższości techniki elektromechanicznej nad mechaniczna. Jak twierdzi Torres y Quevedo, to z powodu używania wyłącznie metody mechanicznej projekt Charlesa Babbage’a zakończył się fiaskiem. On sam zaczynał od stosowania tej metody, jednak do proponowanych przez niego rozwiązań zainspirowały go konstrukcje urządzeń, które projektował i budował jako inżynier. Rozwiązania te nie tyko okazały się pionierskie, lecz także doprowadziły go do przełomowych wyników teoretycznych. Mimo to osiagnięcia Torresa y Quevedo wciąż jeszcze pozostają nieznane. Mam nadzieję, że niniejsza praca pokazuje, iż warto się im bliżej przyjrzeć.

18 B. Randell, From Analytical Engine to Electronic Digital Computer, dz. cyt., s. 341 . 


\section{Summary}

\section{Torres y Quevedo's idea of automation as a contribution to the} development of computer science

The aim of this article is to indicate that the ideas of Leonardo Torres y Quevedo presented in his short Essays on Automatics constitute essential link between early Babbage's concepts of analytical engine and modern computer science. These ideas include definition of automatics, classification of automata, theoretical basis for robotics, electromechanical engineering, modern concept of chatbot, the importance of algorithm and last but not least floating point arithmetic.

Keywords Leonardo Torres y Quevedo, analytical engine, artificial intelligence, robotics, automatics, computer science

\section{Bibliografia}

Descartes R., Rozprawa o metodzie, tłum. W. Wojciechowska, Kraków 1950.

González de Posada F. G., González Redondo F. A. G., Leonardo Torres Quevedo (1852-1936). 2a Parte: Automática, máquinas analiticas, „La Gaceta de la RSME” vol. 8.1 (2005), s. 267-293.

Randell B., From Analytical Engine to Electronic Digital Computer: The Contributions of Ludgate, Torres, and Bush, „Annals of the History of Computing" 4 (1982), s. 327-341.

Russell S., Norvig P., Artificial Intelligence: A Modern Approach, Prentice Hall 2009.

Torres and His Remarkable Automatic Devices, „Scientific American Supplement", nr 20796 listopada (1915), s. 297.

Torres y Quevedo L., Essays on Automatics. Its Definition - Theoretical Extent of Its Applications, [w:] The Origins of Digital Computers: Selected Papers, ed. B. Randell, Berlin-Heidelberg-New York 1982, ss. 89-107.

Vigneron H., Les Automates, „La Nature” 2141 (1914), s. 56-61. 